\title{
Aboriginal Women Experiencing Violence
}

\section{Andrea Heavener}

Throughout nursing thus far, I have been fortunate to come across a wide variety of experiences. Naturally, some have left a lingering impact on me. While practicing on a neuro-trauma unit, I had a patient that was a victim of severe abuse at the hands of her partner. Upon discharge, there was no information provided to her about support services, and I felt we severely let her down in the healthcare system. She was Aboriginal. This experience left me with a strong desire to learn more about violence against women, specifically Aboriginal women, and learn more about how I could better help these women in the future. In this paper, my demographic of focus is Canadian Aboriginal women, and the mechanism of traumatic injury is violence. I will utilize a socioecological framework to assess the vulnerability of my specified population, and I will discuss implications for nursing research, practice, and education.

As reported by Statistics Canada (2011a), "Aboriginal women reported experiencing close to 138,000 incidents of violence and were almost three times more likely than non-Aboriginal women to report having been a victim of a violent crime" (p. 7).

rate per 1,000 female population age 15 or older

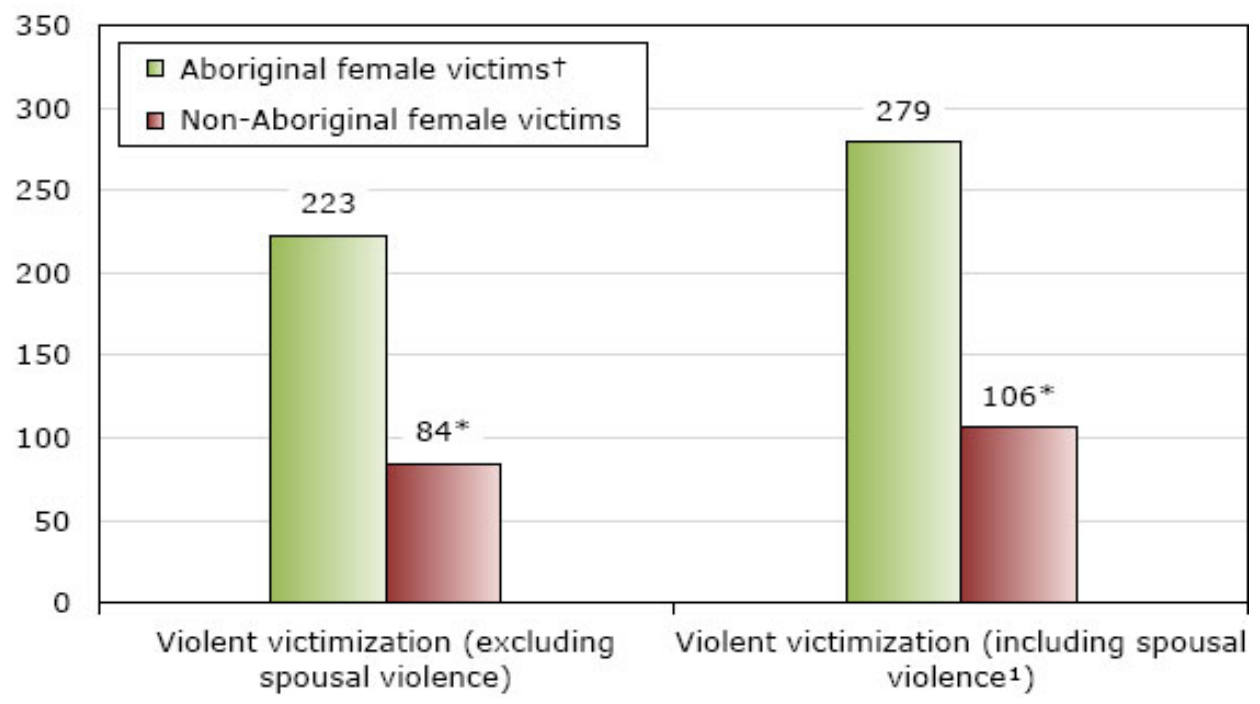

Those statistics are also reported by Battered Women's Support Services (2013), and by the Native Women's Association of Canada (2010). Another shocking statistic is reported by Amnesty International (2004), stating that Aboriginal women are five times more likely to die as the result of violence. So according to 
those sources, Aboriginal women are a greater risk of not only being a victim of violence, but also have a greater risk of dying due to that violence. With Aboriginal women being violently victimized at a much higher rate than nonAboriginal women, one must wonder why that occurs. I will analyze this situation using the Injury Iceberg Model to gain a better understanding of Aboriginal women's susceptibility to violence. This model analyzes the situation from five levels: intra-personal, inter-personal, organizational, community, and societal (Hanson et al., 2005).

To begin, I will start at the tip of the iceberg and discuss the intra-personal factors that may increase an Aboriginal woman's likelihood of being a victim of violence. This category was challenging for me, as I believe no woman deserves to be beat up, regardless of her behaviors. Hanson et al. (2005) include knowledge, life experience, and biology in this intra-personal category. Life experience may include witnessing violence as a child. The Canadian Women's Foundation (2013) reports that children who grow up in a violent home are at an increased risk of being a victim of violence as an adult, or have an increased likelihood of becoming an abuser (p. 5). Not only does witnessing violence as a child impact the life experiences of Aboriginal women, it also impacts their knowledge and attitudes. If violence is a regular occurrence in their life, their attitude is that of normalcy towards violence. In terms of biological factors, there is no genetic component or physical trait that Aboriginal women have which would cause them to be victims of violence more frequently than non-Aboriginal women. However, Totten (2010) published a study indicating the possible links between Fetal Alcohol Spectrum Disorder and increased violence towards women in the Aboriginal community. Unfortunately the results were not conclusive, but it was a suggested linkage between biological factors and increased violence.

Next, I will focus on the inter-personal factors. This category includes family, friends, and peers; it is revolved around the physical environment and social networks surrounding these women (Hanson et al., 2005). The immediate physical environment may play a part in the increased violence. Health Canada (1999) reported that crowded housing can lead to a variety of health problems, and can cause a risk for an increased rate of violence. Statistics Canada (2011b) states that "14\% of First Nations women and girls were living in crowded dwellings, over three times higher than the proportion of non-Aboriginal females (3\%)" (p. 22). This over-crowding in the immediate physical environment may put the Aboriginal women at a higher risk of becoming a victim of violence.

Aboriginal women can also be impacted by their surrounding social networks. Katerndahl et al. (2013) discuss how abused women tend to have minimal social 
support, and states that: "Women in violent relationships tend to choose friends in similar violence-provoking environments as themselves" (p. 1959). This again promotes the idea of violence as a normalized condition in the community. There are many intertwined connections between inter-personal and intrapersonal factors. For instance, the exposure to violence in the home is an interpersonal factor when it involves the family. Unfortunately, not many studies have been conducted looking at the relationships between physical environments, social networks, and violence; it is challenging to analyze interpersonal factors due to the lack of evidence.

Now, the injury iceberg examines organizational factors leading up to the violence against Aboriginal women. The organizational portion examines associations and social institutions such as health organizations, clubs, and work (Hanson et al., 2005). A quick internet search showed me that health organizations, specifically for Aboriginal Women, are few and far between. The National Aboriginal Health Organization is a resource for information, but is only accessible via internet or phone. Sadly, there are even fewer physical centers for Aboriginal women that are traumatized by violence. The Women Against Violence Against Women (2014) foundation has an Aboriginal program that uses culturally relevant education, healing tools, and counseling for women that are victims of violence: it is a beautiful program, but only available in Vancouver. Ontario has a similar haven for Aboriginal women that experienced violence, and offers holistic care meeting their unique needs (Minwaashin Lodge, 2010). Despite some centers of excellence such as those just listed, there are very few resources and health organizations available for Aboriginal women. Aboriginal Consulting Services (2013) has healing circles to develop healthy coping methods and learn how to better deal with an abusive family member; however, to join this program you have to have been a victim in the past (para. 2). Ideally, primary health education regarding violence prevention would be offered in the communities, rather than focusing on the post-violence treatment.

As I move towards the bottom of the injury iceberg, the other underlying causes of violence towards Aboriginal women become more apparent. These include ethnicity, social class, roads, and public facilities (Hanson et al., 2005). Although roads and public facilities may seem to be irrelevant to trauma issues, they indeed have an impact. Stastna (2011) discussed the poor conditions on First Nation reserves, and identifies that many communities are isolated due to poor roads or lack of roads during winter months. If a woman is a victim of violence, the option of leaving is taken away when there is no physical exit out of the community. Therefore, she may have no choice but to expose herself to the violent situation again in the future. Public facilities such as libraries and recreation centers are not often found on First Nations reserves either, providing no space to spend time other than at home (Canada's Economic Action Plan, 


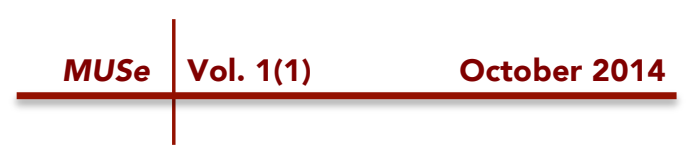

2013). Aboriginal women can experience violence in any setting: despite those conditions being on reserves only, they acknowledge certain points that may increase the violence rates.

Another organizational factor in the injury iceberg is social class (Hanson et al., 2005). Socio-economic status (SES) is a major contributing factor to violence against Aboriginal women. Malcoe, Duran, and Montgomery (2004) study the link between socio-economic status and violence, and found that a lower SES can indicate a higher risk of violence. According to Statistics Canada (2006), twice as many Aboriginals had income below the low income cut off line than non-Aboriginals, and non-Aboriginals were twice as likely to complete secondary school. Without listing every statistic, there is good indication that Aboriginal people are at a disadvantage when looking at socio-economic status. Dauod et al. (2013) published a study that examined the relationship between low socioeconomic position and high rates of violence against women in the Aboriginal community. The findings concluded that a definite relationship exists, and suggests that the risk of being a victim of violence could be reduced by forty percent if Aboriginal women had the same SES as non-Aboriginal women ( $p$. 281). This was the first study of this kind, but the staggering results will hopefully spur more research looking at the great importance of socio-economic status in relation to violence against women.

Last but not least, the injury iceberg's bottom level is societal factors. This component can be elaborated on from many viewpoints. National psyche, government policy, health facilities, education, and economics all play a major role in the increased level of violence towards Aboriginal women (Hanson et al., 2005). I have already discussed education and health facilities, but I will state the major points again. As mentioned previously, Aboriginal women are less likely to complete high school, and are less likely to achieve post-secondary education than non-Aboriginal women (Statistics Canada, 2011b). This may put them in a lower social class, which can lead to an increased risk of violence (Dauod et al., 2013). Also, I mentioned the National Aboriginal Health Organization as one of the few resources that can provide culturally relevant information. On further research, I discovered that it is only an information bank because budget cuts lead to shutting the doors of its physical centers (National Aboriginal Health Organization, 2013). The economic situation impacts violence against Aboriginal women by cutting funding to such centers and facilities, rather than funding prevention and education centers to help women heal, the money will go to helping these women once they arrive at the hospital with a traumatic injury from violence. As the Canadian Institute for Health Information (2003) points out, victims of violence use more healthcare resources than women who have not been victimized. 


\section{Andrea Heavener}

Another societal component that may increase the rates of violence against Aboriginal women is the national psyche. Just through conversation with peers, I have seen some negative attitudes towards the Aboriginal population, and these can be quite widespread. Veenstra (2009) identifies that race and discrimination can play a major role in different groups seeking healthcare due to a power imbalance (p. 539). Tang and Browne (2008) discuss discrimination against Aboriginal people in the Canadian healthcare system. They state that "patients subject to profiling in society may expect how to be treated and thus what decision they will make in regards to when, where, or whether to seek health care." (p. 123). If Aboriginal women expect poor treatment by healthcare providers, they may never seek help or educational resources for fear of judgment. Although healthcare is supposed to be non-judgmental, it appears this is not happening. Another supposedly non-judgmental system is the justice system, where these women can turn to for help before or after violence against them. It seems this system is also failing because inherent racism is not protecting Aboriginal women from the offenders (Dylan, Regehr, \& Alaggia, 2008). Despite Canada's reputation for being accepting of everyone, evidence shows blatant racism towards Aboriginal people: the national psyche may be partly responsible for increasing the rates of violence against Aboriginal women.

One more societal component that cannot be overlooked is the continuing impact of residential schooling and colonization. While some may say that the past is the past, evidence proves the lingering negative effects that residential schools have on the Aboriginal population. It is suggested that patriarchal dominance was introduced to Aboriginals during Euro-Colonization and that if Aboriginal men are feeling oppressed they will take it out on the women (Brownridge, 2008). Kubik, Bourassa, and Hampton (2009) also discuss residential schools, and the negative results of the Indian Act: forced assimilation, loss of rights, and multiple abuses have led to the increased violence towards Aboriginal women. Over time, Aboriginal women have lost positions of respected community members and been replaced by men in the new patriarchal system. As a result, violence against Aboriginal women is elevated. Kubik, Bourassa, and Hampton (2009) suggest that higher rates of violence towards Aboriginal women continue a cycle of addiction and further victimization (p. 23). It is clear that the societal factors of the injury iceberg play a major role in the high rates of violence against Aboriginal women. With that in mind, there is no simple solution to decrease the violence rates, and one must consider so many elements before trying to create an answer.

Now that the injury iceberg has identified the socio-ecological factors in violence against Aboriginal women, I can begin to think of how to possibly improve the situation. There are definite implications for nursing education, research, and practice. Although, I can remember Aboriginal guest speakers and learning about cultural safety, I do not feel I have received much education specific to caring for the Aboriginal population. Stansfield and Browne (2013) 


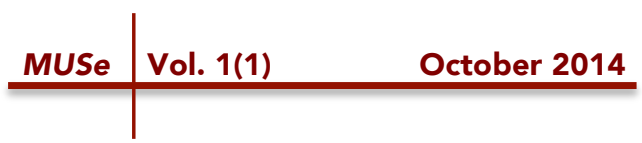

feel that adding Indigenous knowledge to nursing curriculum can provide a broader perspective to base my practice on. However, they also state the importance of having an appropriate educator, rather than someone who will promote cultural differences, and ignore the legacy of colonization (p. 7). Mahara, Duncan, Whyte, and Brown (2011) identify similar themes and make suggestions for education about culturally safe care of Aboriginal people. These include a more diverse faculty, a student-Elder-nurse network, and development of a culturally safe framework. It would be interesting for students and staff to be given the opportunity to expand our knowledge of Aboriginal people, and I think it could really enhance our future careers.

The suggestions I mentioned above are for education regarding culturally safe care of Aboriginal people. Despite the suggestions being very manageable with the potential to make great improvements, they are not specific to women that are victims of violence. As a student, I felt completely overwhelmed when caring for my patient that had been violently traumatized. I could not recall anything learned in school to help me be a better nurse for her. Amar (2008) brings attention to this knowledge deficit among nursing students and suggests simple additions to curriculum to improve our competency. The main points are the understanding of the problem of violence against women, examining societal myths, and exploring personal beliefs (pp. 14-15). Even with that small amount of preparation, I could have cared for my patient more effectively. Despite many nursing schools identifying the need for education about violence against women, it is suggested that an individual faculty member's interest in the subject determines the likelihood of it being taught (Hoff \& Ross, 1995). If education surrounding Aboriginal people and education about violence against women were both included more frequently in nursing education, we would be better prepared after graduation to help these women.

There are also implications for nursing research regarding the increased rates of violence against Aboriginal women. Most obvious to me, is the need for more research in the areas of violence against Aboriginal women, as there are many gaps in the literature. Amnesty International (2004) provides suggestions in an effort to lessen the violence experienced by Aboriginal women, including the need for increased federal funding for research (p. 15). Much of the information around Aboriginal women's experiences with violence is from statistics rather than subjective telling. If more articles included personal testimonies instead of purely charts and numbers, I feel the nurses could connect more with the cause. Also, there is an Aboriginal Nurses Association of Canada that publishes a journal called The Aboriginal Nurse. Perhaps there could be more joint collaboration between that publication and the Canadian Nurse magazine. That way, current and relevant research could be shared between groups, and our knowledge base could be expanded. Knowledge is power, and the more nurses know, the better we can care for our patients. 


\section{Andrea Heavener}

Finally, there are implications for the nursing profession as a whole. Increased rates of violence against women are not an issue that we should turn our backs on. First and foremost, nurses need to be aware of this issue and the deeper roots that cause violence against women. Rather than blaming the victim, nurses can advocate for their patients and promote the idea that the healthcare system is non-judgmental. While caring for my patient, I got the impression that many nurses had given up on women like her, and expected to see her back again in the future. I would also recommend nurses become familiar with community resources for violently traumatized women, so they can pass this information to their patients. If I had known about even a website, I could have given my patient something to leave the hospital with. The following suggestions can improve the nursing profession and can possibly help decrease the violence against Aboriginal women.

Working with the Aboriginal population can be challenging for nurses that have little experience with this demographic. Foster (2006) provides some simple suggestions that can increase the effectiveness of nurse-patient interactions when the patient is Aboriginal. Gaining knowledge of political decisions on Aboriginal people, recognizing the racism they face, and understanding they may have a biased view of healthcare can all help nurses better care for their Aboriginal patients (pp. 29-30). After a relationship is established, it is easier to ask specifics about their culture that may impact their hospital experience. However, Blackman (2009) suggests that nurses must first become comfortable with the idea of cultural competency before trying to learn about specific cultures. Cultural safety and competency occur when the nurses acknowledge their own cultural beliefs, and when the patient is comfortable addressing their own cultural values in the hospital setting (Harding, 2013). For instance, when the nurse and patient can openly discuss the patients' culture, there is a culturally safe environment. Again, these suggestions apply to all Aboriginals, not just women victims of violence. Although they are broad, they are applicable.

Next, I will focus on nursing improvements for dealing with victims of violence. Due to gaps in the literature, there were no suggestions focused strictly on Aboriginal women. However, these tips for nurses are useful for any woman victimized by violence, regardless of ethnicity. One practice change that nurses can do easily is to refer to women as survivors rather than victims (Hawley \& Hawley Barker, 2012). This can lead to a societal change, and takes the blame off the woman. In the hospital, the first challenge that nurses face is identifying that violence was the cause of injury. Allard (2013) suggests routine screening for all patients, so that nurses do not have to try and distinguish victims of violence from other patients (p. 14). She also suggests that pamphlets and hotline numbers are in plain sight for anybody not willing to ask (p. 16). With that in mind, nurses should add some questions to their routine assessment to improve their practice. These questions could include: "Did another person cause these injuries?" (Hawley \& Hawley Barker, 2012, p. 32). Hawley and Hawley Barker 


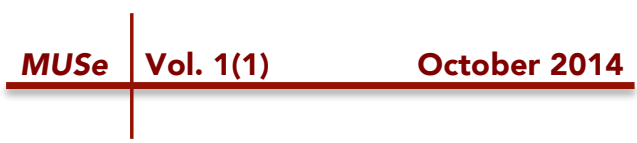

(2012) also stress the importance of accurate charting, as it is a legal record and could be used in court if the offender if being charged (p. 36). These suggestions are implications for the nursing practice that can be put into use in a hospital setting. Unfortunately, they do not effectively prevent violence against women. Preventative measures would be ideal, as right now the focus is on treating the woman after the violence has occurred.

In this paper, I discussed the increased rates of violence against Aboriginal women. The issue was assessed from a socioecological viewpoint and included intra-personal, inter-personal, organizational, community, and societal factors. There are definite implications for nursing education, research, and practice. Sadly, due to many holes in the literature, there are very few implications that deal specifically with Aboriginal women. Also, many suggested practice changes are put in place after the violence has occurred, rather than as prevention tools. I feel that raising awareness about violence against Aboriginal women is a key part in our role as nurses. These numbers astonished me, and the lack of resources was even more surprising. We have the ability to advocate for change and encourage more funding put towards prevention programs. Aboriginal women are much more likely than non-Aboriginal women to be victims of violence, and this is not an issue that should be kept in the dark. Ultimately, if more people know about this issue, more people will want to change it.

\section{References}

Aboriginal Consulting Services. (2013). Circle of Safety Program. Retrieved from: www.http://aboriginalconsultingservices.ca/

Aboriginal Nurses Association of Canada. (2012). Publications: The Aboriginal Nurse. Retrieved from: www.anac.on.ca

Allard, C. (2013). Caring for people who experience domestic abuse. Emergency Nurse, 21(2), 12-16. Retrieved from: http://rcnpublishing.com/journal/en

Amar, A. (2008). Violence education in nursing: Critical reflection on victims' stories. Journal Of Forensic Nursing, 4(1), 12-18. doi:10.1111/j.19393938.2008.00002.x

Amnesty International. (2004). Stolen sisters: Discrimination and violence against Indigenous women in Canada. Retrieved from: www.amnesty.org

Battered Women's Support Services. (2013). The facts on violence against women. Retrieved from: www.bwss.org

Blackman, R. (2009). Knowledge for practice: Challenges in culturally safe nursing practice. Contemporary Nurse: A Journal For The Australian Nursing Profession, 32(1), 211-214. Retrieved from: www.contemporarynurse.com 


\section{Andrea Heavener}

Brownridge, D. A. (2008). Understanding the elevated risk of partner violence against Aboriginal women: A comparison of two nationally representative surveys of Canada. Journal of Family Violence, (23), 353- 367. doi:10.1007/s10896-008-9160-0

Canada's Economic Action Plan. (2013). Health Services in First Nations Communities. Retrieved from: www.actionplan.gc.ca

Canadian Institute for Health Information. (2003). Women's health surveillance report. Retrieved from: www.cihi.ca

Canadian Women's Foundation. (2013). Moving women out of violence. Retrieved from: www.canadianwomen.org

Daoud, N., Smylie, J., Urquia, M., Allan, B., \& O'Campo, P. (2013). The contribution of socio-economic position to the excesses of violence and intimate partner violence among Aboriginal versus non-Aboriginal women in Canada. Canadian Journal Of Public Health, 104(4), e278-83. Retrieved from: http://www.cpha.ca

Dylan, A., Regehr, C., \& Alaggia, R. (2008). And justice for all? Aboriginal victims of sexual violence. Violence Against Women, 14(6), 678-696. doi:10.1177/1077801208317291

Foster, C. (2006). What nurses should know when working in Aboriginal communities. Canadian Nurse, 102(4), 28-31. Retrieved from: http://www.canadian-nurse.com/

Hanson, D., Hanson, J., Vardon, P., McFarlane, K., Lloyd, J., Muller, R., \& Durrheim, D. (2005). The injury iceberg: An ecological approach to planning sustainable community safety interventions. Health Promotion Journal of Australia, 16(1), 5-10. Retrieved from: http://www.healthpromotion.org.au/journal

Harding, T. (2013). Cultural safety: A vital element for nursing ethics. Nursing Praxis in New Zealand, 29(1), 4-11. Retrieved from: www.nursingpraxis.org

Hawley, D. A., \& Hawley Barker, A. C. (2012). Survivors of intimate partner violence: implications for nursing care. Critical Care Nursing Clinics Of North America, 24(1), 27-39. Retrieved from: http://www.ccnursing.theclinics.com/

Health Canada. (1999). A second diagnostic on the health of First Nations and Inuit people in Canada. Health Canada, Ottawa. Retrieved from: www.hcsc.gc.ca

Hoff, L., \& Ross, M. (1995). Violence content in nursing curricula: Strategic issues and implementation. Journal Of Advanced Nursing, 21(1), 137-142. doi:10.1046/j.1365 2648.1995.21010137.x

Katerndahl, D., Burge, S., Ferrer, R., Becho, J., \& Wood, R. (2013). Differences in social network structure and support among women in violent relationships. Journal Of Interpersonal Violence, 28(9), 1948-1964. doi:10.1177/0886260512469103 


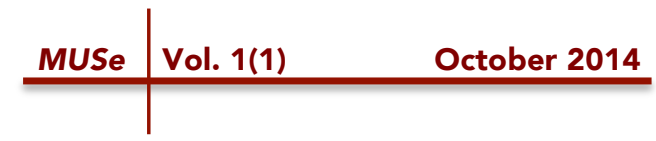

Kubik, W., Bourassa, C., \& Hampton, M. (2009). Stolen sisters, second class citizens, poor health: The legacy of colonization in Canada. Humanity \& Society, (33), 18-34. Retrieved from: http://has.sagepub.com

Mahara, M., Duncan, S. M., Whyte, N., \& Brown, J. (2011). It takes a community to raise a nurse: Educating for culturally safe practice with Aboriginal Peoples. International Journal Of Nursing Education Scholarship, 8(1), 1-13. doi:10.2202/1548-923X.2208

Malcoe, L.H., Duran, B.M., \& Montgomery, J.M. (2004). Socioeconomic disparities in intimate partner violence against Native American women: $A$ cross-sectional study. BMC Med,

2(20). Retrieved from: www.biomedcentral.com

Minwaashin Lodge. (2010). Aboriginal Women's Support Services. Retrieved from: www.minlodge.com

National Aboriginal Health Organization. (2013). About. Retrieved from: www.naho.ca

Native Women's Association of Canada. (2010). Fact sheet: Violence against Aboriginal women. Retrieved from: www.nwac.ca

Stansfield, D., \& Browne, A. J. (2013). The relevance of Indigenous knowledge for nursing curriculum. International Journal Of Nursing Education Scholarship, 10(1), 1-9. doi:10.1515/ijnes-2012-0041

Stastna, K. (2011). Shacks and slop pails: infrastructure crisis on native reserves. CBC News. Retrieved from: www.cbc.ca

Statistics Canada. (2006). Census of Population. Retrieved from: www.statcan.gc.ca

Statistics Canada. (2011a). Violent victimization of Aboriginal women in the Canadian provinces, 2009. Statistics Canada Catalogue no. 85-002-X. Retrieved from: www.statcan.gc.ca

Statistics Canada. (2011b). Women in Canada: A Gender-based Statistical Report. Statistics Canada Catalogue no. 89-503-X. Retrieved from: www.statcan.gc.ca

Tang, S., \& Browne, A. (2008). 'Race' matters: Racialization and egalitarian discourses involving Aboriginal people in the Canadian health care context. Ethnicity \& Health, 13(2), 109-127. doi:10.1080/13557850701830307

Totten, M. (2010). Investigating the linkages between FASD, gangs, sexual exploitation and woman abuse in the Canadian Aboriginal population: A preliminary study. First Peoples Child \& Family Review, 5(2), 9-22. Retrieved from: http://www.fncaringsociety.com/

Veenstra, G. (2009). Racialized identity and health in Canada: Results from a nationally representative survey. Social Science \& Medicine, 69(4), 538-542. doi:10.1016/j.socscimed.2009.06.009

Women Against Violence Against Women. (2014). Aboriginal Women's Services. Retrieved from: www.wavaw.ca 